\title{
Fisn

\section{Interdisciplinaridade e Educação na perspectiva de uma pedagogia hermenêutica}

\author{
Interdisciplinarity and Education in the perspective of a hermeneutical \\ pedagogy
}

\section{José Pedro Boufleuer}

Professor doutor na Universidade Regional do Noroeste do Estado do Rio Grande do Sul, ljuí, Rio Grande do Sul, Brasil.

jospebou@unijui.edu.br - https://orcid.org/0000-0003-3926-5164

Leandro Renner de Moura

Professor na Universidade de Cruz Alta, Cruz Alta, Rio Grande do Sul e na Universidade Regional do Noroeste do Estado do Rio Grande do Sul, ljuí, Rio Grande do Sul, Brasil.

leandro.renner@unijui.edu.br - https://orcid.org/0000-0002-6672-4963

Recebido em 01 de novembro de 2018

Aprovado em 09 de janeiro de 2020

Publicado em 13 de maio de 2020

\section{RESUMO}

Este ensaio visa enfrentar o tema da interdisciplinaridade na educação baseando-se na filosofia hermenêutica de Hans-Georg Gadamer (2012). A motivação do estudo tem a ver com o modo como a interdisciplinaridade vem sendo recepcionada nos espaços de formação humana e com os pressupostos que, nem sempre problematizados, sustentam este conceito no âmbito das práticas pedagógicas. Proliferou-se nas últimas décadas a noção de que a interdisciplinaridade representa o modo prático pelo qual a educação escolar responderia à crescente desarticulação temática das áreas do conhecimento. Este contraponto, no entanto, age em perspectiva técnica e sob um tipo de racionalidade que obscurece a experiência da vida humana com o conhecimento. Por essa razão, o propósito desta reflexão é indicar outro horizonte de compreensão que reitera o esforço retrospectivo da hermenêutica para recobrar a unidade da vida nos processos de comunicação e de aprendizagem dos conhecimentos. Inicialmente, a fim de observar como a interdisciplinaridade adquiriu lugar no debate teórico e na legislação educacional brasileira, realiza-se uma checagem virtual nos Parâmetros Curriculares Nacionais (PCNS, 1997; 1998) com o intuito de destacar as variações de sentido mais evidentes. Em seguida, busca-se nos pressupostos da hermenêutica filosófica a tematização do mundo humano pela linguagem e a recuperação do diálogo como experiência fundante da constituição do mundo humano. Por fim, a pesquisa propõe os desdobramentos de uma concepção 


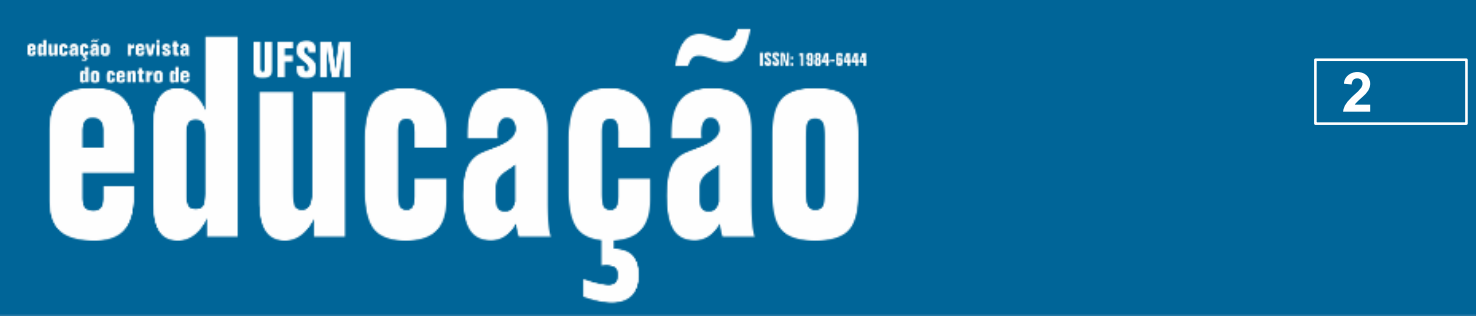

ISSN: 1984-6444 | http://dx.doi.org/10.5902/1984644435441

hermenêutica da interdisciplinaridade na esteira do diálogo gadameriano, sendo neste horizonte teórico que o presente ensaio situa a interdisciplinaridade nos processos de formação humana.

Palavras-chave: Interdisciplinaridade; Educação; Pedagogia hermenêutica.

\section{ABSTRACT}

This essay aims to address the issue of interdisciplinarity in education based on the hermeneutic philosophy of Hans-Georg Gadamer (2012). The motivation of the study has to do with the way in which the interdisciplinarity has been received in the spaces of human formation and with the presuppositions that, not always problematized, support this concept in the scope of pedagogical practices. The notion that interdisciplinarity represents the practical way in which school education responds to the growing thematic disarticulation of knowledge areas has proliferated in recent decades. This counterpoint, however, acts in technical perspective and under a kind of rationality that obscures the experience of human life with knowledge. For this reason, the purpose of this reflection is to indicate another horizon of understanding that reiterates the retrospective effort of hermeneutics to recover the unity of life in the processes of communication and learning of knowledge. Initially, in order to observe how interdisciplinarity has taken its place in the theoretical debate and the Brazilian educational legislation, a virtual check in the National Curricular Parameters (PCNS, $1997,1998)$ is carried out in order to highlight the most obvious variations of meaning. Then, we look at the assumptions of philosophical hermeneutics the thematization of the human world by language and the recovery of dialogue as a founding experience of the constitution of the human world. Finally, the research proposes the unfolding of a hermeneutic conception of interdisciplinarity in the wake of the Gadamerian dialogue, being in this theoretical horizon that the present essay places interdisciplinarity in the processes of human formation.

Keywords: Interdisciplinarity; Education; Hermeneutical pedagogy.

\section{Introdução}

O tema da interdisciplinaridade coloca-se, em contextos de formação humana, como uma espécie de antídoto ao crescente processo de esfacelamento da experiência da vida diante de formas de conhecimento que, muitas vezes, ignoram o fato de constituírem incursões apenas parciais no mundo. Como consequência disso, para além dos previsíveis riscos à coletividade humana que já não vislumbra um sentido articulador para o seu mundo comum, ou sentidos minimamente articulados no âmbito de suas realizações, o próprio sujeito individual encontra dificuldades para 


\section{HEM Eutuabal}

ISSN: 1984-6444 | http://dx.doi.org/10.5902/1984644435441

se perceber numa relação temática com o todo, com consequências práticas no que concerne à elaboração de sentidos para a sua vida.

Não poucas vezes, o discurso da interdisciplinaridade tem sido posto como uma solução para os problemas de convivência entre diferentes áreas de conhecimento ou diferentes tipos de intervenção prática no mundo. Via de regra, porém, tal discurso carece de uma indicação mais clara de seus pressupostos teóricos, ou, então, assume como seus pressupostos os mesmos que orientam o fazer da ciência de ponta, em que se associam, por conveniência, campos de saberes em função de uma ação ou intervenção específica. Se tal associação de campos de saber, legítima e desejável, projeta novas possibilidades no âmbito do conhecimento, inclusive para o desenvolvimento de novos produtos ou de novas tecnologias, isso não indica, necessariamente, um modo pertinente ou fecundo do que seria o operar interdisciplinar em processos de formação humana, como é o caso da educação escolar.

Aos processos de formação humana cabe, antes de tudo, acolher as novas gerações no mundo mediante a explicitação de como estabeleceram-se e mantiveram-se padrões sociais e culturais considerados válidos. Isso significa que em educação interessa um movimento mais propriamente retrospectivo do que prospectivo, ou seja, interessa uma reflexão acerca da forma como os humanos têm produzido mundo. Em não fazendo tal reflexão, ou em não tematizando como humanos criam e mantêm a realidade do mundo, ao discurso da interdisciplinaridade resta um mover-se nos meandros das epistemologias específicas das diferentes disciplinas, com o que se depara com dificuldades para o estabelecimento de uma perspectiva teórica capaz de sustentar uma prática pedagógica articuladora da unidade da experiência humana. Além disso, ao se entender como uma prática articulada no âmbito do operar próprio das disciplinas, tal discurso pressupõe que o campo epistemológico deixou de ser problemático, entendendo ser suficiente juntar as incursões parcializadas para recobrar a unidade do conhecimento e o seu vínculo com a vida.

A perspectiva que aqui nos orienta é de que a interdisciplinaridade, entendida como possível contraponto ao esfacelamento da experiência vivida em processos de 
ISSN: 1984-6444 | http://dx.doi.org/10.5902/1984644435441

formação humana, exige um tipo de articulação que recupere o pano de fundo do mundo da vida do qual as disciplinas emergiram e se estabeleceram com seus recortes temáticos e respectivas metodologias com vistas à produção de saberes objetiváveis. Para fazer esse percurso teórico nos valemos da filosofia hermenêutica de Gadamer (2012; 2002), que em seu esforço reflexivo tem demonstrado que o conhecimento resultante dos processos epistêmicos, metodologicamente controlados, perde o seu vínculo com a experiência mundana e já não é percebido como um verdadeiro acontecimento. Em outros termos, é como se a verdade mais profunda da experiência da vida já não pudesse ser expressa de modo adequado, uma vez que o conhecimento se encontra como que "terceirizado" em relação aos sujeitos que o produziram, mitigando, consequentemente, o compromisso ético fundamental da sua razão de existir.

Pelo caminho da hermenêutica acreditamos ser possível indicar para um diálogo interdisciplinar que restabeleça as relações vitais que articulam o homem com suas produções nos âmbitos da cultura e da sociabilidade. Com isso acreditamos, também, que os processos de formação humana, como os implementados na educação escolar, possam vir a ser percebidos como inserção no próprio mundo da vida pela aprendizagem significativa dos diferentes saberes, sempre compreendidos na historicidade presente.

Assim posicionados, buscamos, no presente artigo, enfrentar o tema da interdisciplinaridade na educação principiando por uma análise do modo como ele tem aparecido no debate teórico no Brasil e de que forma ele foi, aos poucos, adquirindo um lugar na própria legislação educacional, como na LDB de 1996 e nas Diretrizes Curriculares Nacionais estabelecidas em decorrência dessa lei. Na sequência do artigo, destacamos algumas das expressões que recorrentemente aparecem na documentação oficial toda vez que há uma referência ao tema da interdisciplinaridade, chamando a atenção tanto para o viés epistemológico aí presente, como também para um tipo de racionalidade teleológica que parece estar na base de suas compreensões. Num momento seguinte, buscamos na filosofia gadameriana um horizonte teórico para pensar a condição humana e a configuração do mundo a partir da linguagem. Acompanhando o seu percurso de recuperação do diálogo como a expressão do 


\section{HEM Gutrathá}

ISSN: 1984-6444 | http://dx.doi.org/10.5902/1984644435441

modo de nossa constituição como humanos e humanidade, segue como pertinente que a acolhida das novas gerações ao mundo se faça mediante um amplo processo de entendimento linguístico. O diálogo aparece, então, ao modo de uma desejável interlocução entre educadores e educandos, bem como entre os agentes vinculados aos diferentes campos de saber. Assim, é também sob esse horizonte de um mundo que se articula pelo falar e ouvir que vamos situar a interdisciplinaridade nos espaços educativos, perspectiva essa que, entendemos, permite articular a unidade da experiência da vida em processos de formação humana.

\section{A interdisciplinaridade na legislação educacional brasileira}

A interdisciplinaridade vem se destacando na literatura educacional em diversos países desde a década de 60 do século passado. No Brasil é alavancada por intelectuais do campo da filosofia e da educação a partir dos anos 70, principalmente através dos escritos de Hilton Japiassu (1976) e de Ivani Catarina Fazenda (1979). No debate acadêmico a sua tematização está intimamente ligada às transformações culturais que aconteciam na Europa, onde movimentos de contestação, especialmente estudantis, exigiam para as instituições de ensino escolar e superior um estatuto organizativo que fosse renovador e conectado com o mundo da vida e do trabalho.

Nas políticas públicas educacionais, a referência quanto ao que poderia ser um trabalho interdisciplinar nas escolas aparece de modo incipiente nas duas primeiras versões da Lei de Diretrizes e Bases da Educação Brasileira, a de 1961 e a de 1971, sem possuir ainda um caráter normativo ou pedagógico. Encontra-se apenas uma breve caracterização do que seria essa proposta, como por exemplo, "integrar para desenvolver" e um ensino voltado "à formação integral do adolescente". Só a partir da década de 90 a interdisciplinaridade adentra o discurso educacional do país impulsionada pelas reformas curriculares, pela nova versão da LDB (Lei 9.394/96) e pelas Diretrizes Curriculares Nacionais (DCNs) estabelecidas pelo Ministério da Educação. 


\title{
T usy FutlbabुO
}

ISSN: 1984-6444 | http://dx.doi.org/10.5902/1984644435441

É importante salientar que, nesse período, o Brasil ressentia-se da ausência de um projeto nacional de educação mais bem estruturado. As novas formas de organização social, a perspectiva de uma democratização do ensino e a ampliação das oportunidades de acesso à escola por parte das camadas sociais desfavorecidas economicamente levou o Estado brasileiro a repensar as políticas de educação, definindo novas diretrizes com a finalidade de reduzir e eliminar, respectivamente, os baixos níveis de desempenho educacional e o analfabetismo até então registrados. Essa constatação pode ser conferida na reflexão de Fonseca quando reitera o papel dos organismos internacionais na recuperação do desempenho educacional do país.

\begin{abstract}
No período de 1990, o Brasil participou da Conferência Nacional de Educação para Todos, que foi realizada na Tailândia convocada pelo Banco Mundial e outros órgãos internacionais que passa a elaborar novas diretrizes políticas, entre outras, eliminarem o analfabetismo até o final do século. Políticas definidas para as décadas futuras, seu primeiro passo foi pressionar os países dependentes quanto ao seu atraso com relação ao desempenho educacional, e no caso deste estudo, a realidade brasileira. Considerando o compromisso assinado frente à proposta de "Educação para Todos", o Brasil lentamente se apropria e obedece a regra do Banco Mundial e do FMI, incorporando a política do capital financeiro e passa a organizar-se segundo as propostas dos organismos financiadores e busca a elaboração de suas propostas curriculares (FONSECA, 1995, p. 169).
\end{abstract}

Em regra, todo esse trabalho de recuperação da educação brasileira provoca transformações nos ideais próprios da escola, uma vez que caberia a ela concretizar as novas diretrizes e produzir um novo prognóstico da Educação Básica. Na reflexão de Nagel,

a crise no contexto social faz com que a escola mude seu modo de agir, seu procedimento perante as exigências sociais, assumindo outro caráter e consequentemente outras maneiras de proceder. $\mathrm{E}$, nesse momento, entra o Estado para precisar qual o novo papel desejado para essa instituição. (NAGEL, 1992, p. 12).

Esse novo papel proposto à escola surge com a divulgação dos "Parâmetros Curriculares Nacionais", os PCNs. O compromisso firmado no documento foi o de assegurar a formação para o exercício da cidadania, a progressão no trabalho e nos estudos e a participação da comunidade na gestão escolar. E seria nesse documento 


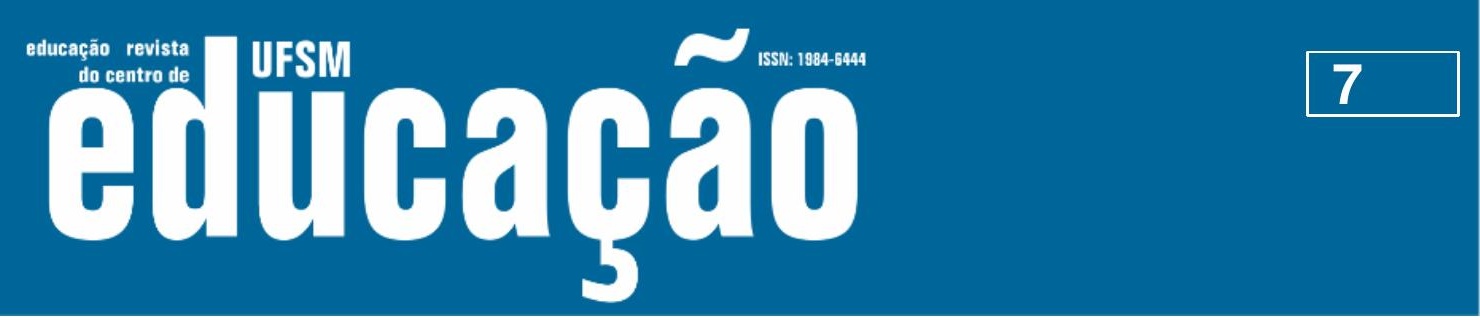

ISSN: 1984-6444 | http://dx.doi.org/10.5902/1984644435441

que a interdisciplinaridade passaria a ter a sua primeira menção legal, respondendo de forma técnica aos baixos índices da educação e constituindo-se uma diretriz orientadora dos processos de ensino e aprendizagem.

Deve-se destacar, contudo, que a interdisciplinaridade não está presente na totalidade dos PCNs, como também não atende de forma direta a um tipo de pensamento academicamente especializado. Quando há a busca da explicitação do tema não se dialoga necessariamente com a produção dos teóricos brasileiros e desconsidera-se o estágio da produção acadêmica internacional. O tema muitas vezes aparece com conotações que desconsideram os fundamentos que embasam, por exemplo, as teorias da aprendizagem até então reconhecidas no campo educacional.

Dito isso, interessa-nos, especialmente, observar a recorrência do tema da interdisciplinaridade no âmbito dos PCNs (MEC, 1997; 1998), bem como o modo como ele é compreendido nesses textos oficias. Através de uma varredura digital nos documentos do Ministério da Educação (MEC), disponíveis na Internet, identificamos a utilização da expressão interdisciplinaridade ou prática interdisciplinar inúmeras vezes. Por isso, trazemos destacadas (em itálico) algumas variações de sentido presentes ao longo dos documentos, introduzindo nossas inferências a fim de mostrar as razões que nos colocam a pensar este tema.

$\mathrm{Na}$ primeira parte dos documentos do Ensino Médio (MEC, 1998) a interdisciplinaridade é considerada uma questão de ordem epistemológica. Isto pode ser constatado quando sugere-se enfrentar a diversidade das formas de conhecimento por um modo de elaboração do saber essencial para o desenvolvimento de competências. No processo pedagógico isto indica para um trabalho de resolução de problemas mediante o uso de diversas especialidades, visto que dão melhores respostas a problemas concretos através do fornecimento de critérios pontuais. Numa segunda leitura aparece a interdisciplinaridade orientada pela necessidade de articular conteúdos. Essa articulação é descrita como uma tentativa de construir pontes entre os conteúdos das disciplinas do currículo escolar. Isso ocorreria através de processos em que os alunos seriam conduzidos a perceber relações de dependência inerentes aos saberes de diferentes componentes. Além disso, a necessidade de articular 


\section{HEM Eutuabal}

ISSN: 1984-6444 | http://dx.doi.org/10.5902/1984644435441

conteúdos mostra outra variação de sentido quando associada à pedagogia. Caberia ao professor a tarefa de meramente sinalizar possíveis pontos de conexão, ação que em boa medida interrompe o compartilhamento de ideias imprescindível nas ambiências de aprendizagem, em nome de uma premissa interdisciplinar técnica e estratégica. A interdisciplinaridade sugerida a partir desta perspectiva seria muito mais uma tentativa de relacionar saberes que mantêm intactas suas fragmentações e especializações, sem a sinalização de um horizonte articulador das diferentes temáticas disciplinares.

$\mathrm{Na}$ continuidade da análise chegamos à noção de interdisciplinaridade na qualidade de uma integração de disciplinas. Diferentemente da articulação de conteúdos antes abordada, trata-se aqui da ideia de uma ampliação do alcance da ação pedagógica exercida pelo professor para além do contexto de sua disciplina e processos particulares de mediação. Embora essa orientação siga o pressuposto de uma percepção mais ampla dos saberes, não fica evidente como seria possível afastar-se de um campo específico de origem para assumir perspectivas que partem de diferentes tematizações. Compreendemos que, da forma como está colocada, a interdisciplinaridade impõe uma atitude complexa de forma aparentemente vaga. Essa postura pedagógica desejada passaria, em primeira instância, por uma explicitação teórica que explicasse a contribuição de um trabalho integrado em processos de formação, seguido de uma reflexão em torno da experiência que autenticamente produz a interação entre os seres. O conceito de interdisciplinaridade dos PCNs que encontramos nos fez imaginar um renovado discurso das epistemologias que não explicita "como" articular ou integrar conhecimentos nem "de que maneira" as relações entre disciplinas são possíveis. Em nossa constatação, a orientação para essas ações continua no elogio à técnica. Como buscaremos argumentar mais adiante, só na forma de um diálogo entre seres humanos isso seria possível, e não por uma pretensa combinação temática e monológica entre áreas como preveem os documentos, como se pudessem os conceitos falarem sozinhos numa compreensão muito mais metodológica do que comunicativa. O diálogo humano, em nosso entender, pode administrar essa possível articulação das disciplinas ao solicitar a presença autêntica dos seres que as operam. 


\section{HEM Gutrathá}

ISSN: 1984-6444 | http://dx.doi.org/10.5902/1984644435441

Sendo assim, o que as variações de sentido destacadas até aqui indicam pontualmente?

Que a interdisciplinaridade citada nos documentos do MEC permanece ancorada nos pressupostos das metodologias científicas, e ainda que tenham contribuído diretamente ao progresso do conhecimento humano, não geram os fundamentos necessários para o debate em questão. Nossa contribuição, portanto, reservará lugar substantivo à linguagem e ao diálogo para enfatizar o sentido hermenêutico do ato pedagógico, compreendendo a interdisciplinaridade como uma postura intelectual apropriada para a reconciliação dos campos científicos pela tematização do mundo da vida na experiência do encontro dialógico.

A busca por um novo sentido, quiçá mais pertinente ao trabalho interdisciplinar na educação passa pela observação de estruturas subjacentes, como a tradição, o pertencimento e a condição da linguagem, as quais transcendem o âmbito da epistemologia e das metodologias especializadas. Envolve, além disso, a responsabilidade com o outro e o exercício da escuta como experiência autorreflexiva da docência. Por esses motivos, a hermenêutica filosófica de Hans-Georg Gadamer $(2012,2002)$ será o suporte teórico da abordagem que faremos, tendo em vista a sua profunda reflexão sobre a experiência do diálogo e por sugerir a suspensão da equação sujeito-objeto, própria das epistemologias, nos processos de aprendizagem e de formação humana em geral.

\section{Linguagem e diálogo na filosofia gadameriana}

Nos estudos de Hans-Georg Gadamer (2002), o espírito de dominação da ciência moderna absolutizou visões e compreensões de mundo e, de alguma forma, favoreceu uma determinação epistemológica na interpretação científica dos últimos séculos. Em contrapartida, leva-nos a pensar de um outro modo e oferece-nos um contraponto alimentado em sua filosofia hermenêutica. Argumenta que a experiência humana não pode ser inserida metodologicamente em estatutos de verdade, uma vez que estes são temporários e imperfeitos. Inversamente, defende que a hermenêtica 


\section{HSW Eutuabal}

ISSN: 1984-6444 | http://dx.doi.org/10.5902/1984644435441

precisa ser concebida como uma abordagem filosófica não absoluta, mas fundada na ilimitada possibilidade de produzir sentidos sobre as coisas.

A preocupação preliminar de Gadamer (2012) esteve em levantar dúvidas acerca dessa segurança depositada nas regras do método científico. No pensar de Berticelli (2004), o diagnóstico de Gadamer (2012) critica o fato dos pensadores iluministas, remanescentes do projeto cartesiano, descartarem a tradição histórica em processos de produção do conhecimento. Em oposição, apresenta outra abordagem em relação ao modo como devemos interpretar um objeto científico, dentro da qual as concepções dogmáticas do período moderno são definitivamente superadas. Segundo o autor, interpretar um objeto de estudo ou investigação significa possuir um entendimento prévio sobre ele, conhecimento este adquirido com as tradições que o intérprete assimilou por estar inserido em determinada cultura.

Nessa contradição, Gadamer (2012) vai ressignificar o lugar da tradição como um conceito necessário para compreender a cultura e a história humana. Em suas reflexões, o conceito de tradição é convergente e também envolve a crença na racionalidade, uma vez que é um fator necessário para o entendimento da linguagem e da compreensão humana. A insatisfação de Gadamer (2012) com relação ao racionalismo estaria na tendência de perceber as dimensões do mundo humano como regulado por regras ou leis de origem natural, em detrimento dos aspectos comportamentais, sociais e culturais desenvolvidos pela humanidade.

O tema da tradição, portanto, como pressuposto dessa compreensão hermenêutica do mundo humano, é visto por Gadamer (2012) como a gênese das coisas, onde se inauguram os sentidos. Vê nisso a porta para a elaboração da noção de preconceitos, que somente são acessíveis movendo-se na linguagem. Será na mediação linguística que o ser emitirá ao outro os seus preconceitos em relação àquilo que os envolve, pois as interpretações produzidas nessa mediação já estão sempre sob a influência da tradição. Em regra, a interpretação de um discurso, de um texto ou de uma obra de arte tem seu início provocado por um preconceito, um pré-juízo que acontece nos humanos em função do seu pertencimento cultural. Para o autor (2002, p. 75) isso "é o que perfaz o movimento semântico de compreender e de interpretar". 


\section{HEM Eutuabal}

ISSN: 1984-6444 | http://dx.doi.org/10.5902/1984644435441

No entendimento de Palmer (1997), essas concepções fazem Gadamer (2012) propor um novo conceito à interpretação científica, quando:

A situação interpretativa não é mais a de uma pessoa que interroga e de um objeto, devendo aquele que interroga construir métodos que lhe tornem acessível o objeto. Pelo contrário, aquele que interroga descobre-se como sendo o ser que é interrogado pelo tema (1997, p. 170).

Nessa alteração conceitual, fica evidente a posição de Gadamer (2012) com relação ao método apresentado na modernidade, especificamente contra o endurecimento da metodologia científica ao modo de uma equação sujeito-objeto. Vemos em sua reflexão que o problema do método pode estar dividido em duas preocupações: a lógica estratégica - que prevê os fins - e a subjetividade - que descarta a tradição. O autor defende que o paradigma da compreensão hermenêutica é, por origem, uma experiência de mundo que não pode ser reduzida a um esquema mental metodológico egocentricamente controlado.

Diferentemente das regras do método propõe a existência dos chamados horizontes interpretativos (horizonte da obra e horizonte do intérprete). No tocante ao acontecimento dialógico entre seres humanos, é possível afirmar que todo ser significa um horizonte, e, por desde sempre estar submetido ao diálogo, encontra no seu interlocutor um outro horizonte, isto é, uma outra leitura de mundo. Dessa situação compreensiva movimentada pela linguagem, segundo Gadamer (2012), surge a fusão de horizontes, no que acreditamos emergir um encontro de perspectivas de mundo, no qual a verdade não terá de ser apenas explicada ou defendida - tal como descreve a filosofia da consciência - mas interpretada à luz da tradição histórica dos participantes.

Entretanto, é necessário considerar que este simples encontro de leituras não é suficiente para que a compreensão aconteça e o acordo entre as partes se estabeleça. É necessário que haja o interesse naquilo que o outro está a dizer, isto é, mais do que uma mera intelecção ou tradução de palavras, mas a compreensão, a interpretação, o deslocamento do próprio ponto de vista para o ponto de vista do outro (BERTICELLI, 2004). Esse encontro de horizontes interpretativos, na reflexão de Lawn, significa, em última instância, "[...] a qualidade da pessoa não dogmática se 


\title{
7 Hsh

ISSN: 1984-6444 | http://dx.doi.org/10.5902/1984644435441

abrir para possibilidade [...], é realmente uma forma de entendimento" (1997, p. 89). Dentro dessa perspectiva, é possível observar o desvelamento do sentido, acessível apenas por meio da atividade comunicativa, a qual pode gerar a condição mínima para que os falantes conquistem o entendimento. Haverá, contudo, em cada sujeito, um diálogo com os referenciais da própria consciência, emergindo disso tudo, o conteúdo simbólico necessário o alcance do consenso.

É a partir deste conjunto teórico que a filosofia gadameriana amplifica o caráter dialógico da experiência humana. Para o pensador alemão, a "autêntica conversação entre os homens" é a engrenagem do entendimento hermenêutico. Na mesma esteira, Lawn (1997, p. 97) salienta que "o verdadeiro nascimento da verdade é o que acontece no diálogo genuíno".

Na passagem a seguir, Gadamer (2012) ilustra a condição do acontecimento dialógico a partir dos princípios da hermenêutica filosófica.

\begin{abstract}
A verdadeira realidade da comunicação humana é o fato de o diálogo não ser nem a contraposição de um contra a opinião do outro e nem o aditamento ou soma de uma opinião à outra. $\mathrm{O}$ diálogo transforma a ambos. $\mathrm{O}$ êxito de um diálogo dá-se quando já não se pode recair no dissenso que lhe deu origem. Uma solidariedade ética e social só pode acontecer na comunhão de opiniões, que é tão comum que já não é nem minha nem tua opinião, mas uma interpretação comum do mundo. (GADAMER, 2012, p. 141).
\end{abstract}

A partir dessas considerações, o diálogo hermenêutico pressupõe o encontro entre dois mundos, duas visões ou imagens de mundo e, principalmente, o interesse que move o ser a conhecer a visão do outro. Para o autor, trata-se de um processo entre pessoas que visa construir intersubjetivamente uma concepção de mundo que se descubra comum. Dentro disso, vale conferir a indagação de Gadamer (2002) sobre o conceito de diálogo: 


\section{U Eutlagha}

ISSN: 1984-6444 | http://dx.doi.org/10.5902/1984644435441

O que é um diálogo? De certo que, com isso, pensamos num processo entre pessoas, que, apesar de toda sua amplidão e infinitude potencial, possui uma unidade própria e um âmbito fechado. Um diálogo é, para nós, aquilo que deixou uma marca. $O$ que perfaz um verdadeiro diálogo não é termos experimentados algo novo, mas termos encontrado no outro algo que ainda não havíamos encontrado em nossa própria experiência de mundo. Aquilo que movia os filósofos a criticar o pensamento monológico é o mesmo que experimenta 0 indivíduo em si mesmo. O diálogo possui uma força transformadora. Onde um diálogo teve êxito ficou algo para nós e em nós que nos transformou. $O$ diálogo possui, assim, uma grande proximidade com a amizade. É só no diálogo (e no rir juntos que funciona como um entendimento tácito trasbordante) que os amigos podem encontrar-se e construir aquela espécie de comunhão onde cada qual continua sendo o mesmo para o outro porque ambos encontram o outro e encontram a si mesmos no outro. (GADAMER, 2002, p. 247).

\section{Educação e interdisciplinaridade na perspectiva do diálogo hermenêutico}

Entendemos que tudo o que vimos até aqui remete a um possível diálogo intelectual como pressuposto aos processos de formação humana, pelo qual docentes e agentes educativos se orientam na busca de novos conhecimentos e do aprimoramento dos saberes já existentes. Nesse horizonte, a interdisciplinaridade deve apresentar-se essencialmente ao modo de um diálogo, pois conforme Fávero (2002),

O diálogo é a relação de um "eu" frente a um "tu". Pressupõe, portanto, a existência de saberes nos dois sujeitos que compõem os polos da relação. $O$ confronto de saberes, porém, requer dos sujeitos a partilha da palavra e a concessão de que seus saberes não são absolutos (FAVERO, 2002, p.114).

Na conversação, há uma responsabilidade mútua em que a palavra é proferida em condições de igualdade, mesmo que os sujeitos tenham posições distintas dentro de uma mesma área de estudo, por exemplo. O diálogo exige humildade para que todos se percebam inacabados, ou seja, que cada qual aprenda a admitir que seu conhecimento não é o último, nem o melhor ou o mais importante. Isso vale também para a hierarquia que impõe níveis de importância entre as disciplinas científicas e, sobretudo, escolares. 


\section{HEM Eutinabá}

ISSN: 1984-6444 | http://dx.doi.org/10.5902/1984644435441

Dentro dessa concepção vemos que a interdisciplinaridade pode ser entendida como uma interação entre intelectuais docentes no aprimoramento da condição de escuta, pois sem ela não há diálogo que se efetive. Gadamer (2002, p. 247) reforça essa noção ao ressaltar que "o que faz um verdadeiro diálogo não é termos experimentado algo de novo, mas termos encontrado no outro algo que ainda não havíamos encontrado em nossa própria experiência de mundo". Por esta razão dizemos que a relação dialógica entre intelectuais pode configurar a "pré-condição" do ato educativo. Essa interação pode significar, filosoficamente, o fenômeno do encontro entre seres de linguagem, os quais só aprendem pela possibilidade da comunicação. Pragmaticamente, numa ação comunicativa cooperada em torno da questão do conhecimento, o sujeito intelectual (docente) encontraria no outro aquilo que, por suposto, não conhece ou domina, configurando, isto, em uma descoberta colaborada de caráter hermenêutico, dentro da qual as expectativas de produzir sentido são infinitas e não totalmente presas em uma episteme ou visão especializada.

Partindo da filosofia gadameriana, Hans-Georg Flickinger, na obra A caminho de uma pedagogia hermenêutica (2010), nos serve de orientação para a continuidade de nossa reflexão. Entende o autor que os desafios atuais da pedagogia passam por uma retomada crítica dos paradigmas do conhecimento e que, junto a essa reconstituição teórica, cabe investigar a crescente adoção do discurso da interdisciplinaridade na educação, o que impõe, também, a procura por fundamentação.

"O fundamento hermenêutico da Interdisciplinaridade" (FLICKINGER,2010, p. 45), como o próprio autor escreve, está na relação entre filosofia e educação. Segundo Flickinger (2010), é esta relação que permite indagar o sentido da educação, contudo, alerta sobre a tentativa ingênua de reunir o saber construído pela humanidade numa visão de totalidade. 


\section{-

ISSN: 1984-6444 | http://dx.doi.org/10.5902/1984644435441

Em vez de insistir nesse objetivo não mais viável, está intensificando-se o debate em torno da possível reconstrução de pontes entre as disciplinas, no intuito de fazer jus à complexidade crescente dos problemas que se nos colocam e que uma só perspectiva de questionamento não consegue mais abarcar. Sem dúvida, é esse o enfoque principal que está sendo visado na busca por modelos novos de cooperação e diálogo científico; modelos que receberam a denominação de "interdisciplinaridade", "transdisciplinaridade" ou "multidisciplinaridade". (FLICKINGER, 2010, p. 46).

A proposta de Flickinger (2010) situa-se na construção de pontes entre as disciplinas, o que não deve representar uma regra ou configurar uma epistemologia, mas uma condição de enfrentamento coletivo das transformações a que passam sociedade e conhecimento. Talvez o que esteja em pauta é, de um lado, o questionamento quanto às abordagens totalizadoras e, de outro, o risco da perda de perspectiva comum entre as áreas.

Essa abordagem caminha em direção ao sentido ético da pedagogia e para a aceitação do "ser diferente" de cada disciplina. Também desvela o caráter dialógico como o sentido verdadeiro da cooperação interdisciplinar e não prevê a eliminação de perspectivas conceituais e temáticas comuns. Pelo contrário, as pontes significam, como já frisamos, o acesso ao saber do outro como um modo construtivo de reavaliar os próprios pressupostos.

o relacionamento entre disciplinas parece-me ser marcado por uma estrutura que permite não apenas descobrir o entendimento específico de cada um quanto ao tema a ser tratado, mas também motivar a autorreflexão sobre os próprios olhares restritos que delimitam seu questionamento. O que está em jogo, nessa referência mútua das disciplinas, remete a um seu fundamento hermenêutico implícito; fundamento este que nos faz entender os pressupostos imprescindíveis para qualquer cooperação interdisciplinar eficiente. (FLICKINGER, 2010, p. 47).

$\mathrm{Na}$ ilustração, a interdisciplinaridade não prevê que conceitos ou procedimentos específicos sejam misturados e aproximados metodologicamente. Não sugere, também, que os humanos envolvidos em práticas interdisciplinares sejam postos em situação constrangedora através da cobrança de um nível intelectual que isso implicaria. Por outro lado, a elaboração de Flickinger (2010) novamente recupera a experiência do encontro para explicar o fundamento dialógico da interdisciplinaridade, 


\title{
T usm Futlbabुa
}

ISSN: 1984-6444 | http://dx.doi.org/10.5902/1984644435441

diferenciando o que seriam as exigências humanas necessárias para o diálogo de uma sequência técnica de pretensões. O próprio autor continua explicando:

\begin{abstract}
o encontro interdisciplinar pressupõe a disposição dos participantes de aceitar a vir ao encontro do outro, ou seja, de abrir-se em direção de interesses e questionamentos que não encontram respaldo e menos ainda base legítima no próprio horizonte temático. Levar o outro a sério significa, antes de tudo, entregar-se à perspectiva por ele defendida, a fim de compreender o porquê dessa sua concepção e avalia-la quanto à sua autenticidade. Somente assim parece ser possível evitar o julgamento precoce e aquela postura dominadora que iria impedir qualquer diálogo interdisciplinar verdadeiro. (FLICKINGER, 2010, p. 52).
\end{abstract}

No diálogo compartilhado com o outro, haverá uma troca de opiniões, ora havendo concordância, ora não. Independentemente disso, não se pode ignorar o que o outro diz, ou, o que a experiência contada de dentro de uma disciplina possa revelar de interessante. Assim, é forçoso pensar sobre o que acreditamos ser um diálogo autêntico e como estaria intimamente associado à pedagogia. De acordo com o autor, nenhuma disciplina pode impor à outra, de modo unilateral, uma perspectiva oficial e indiscutível. Ao invés disso, "cada uma se vê obrigada a expor sua própria perspectiva ao risco de ser contestada à base de argumentos bem fundamentados" (FLICKINGER, 2010, p. 51). Nessa abordagem, o diálogo evidencia a possibilidade da abertura ao contraditório, à pergunta do outro, à sua retórica e à autenticidade da sua contribuição. Com isso, o diálogo interdisciplinar, a partir da reflexão de Flickinger (2010),

não nos abre os olhos para enxergar melhor o que se passa em outras áreas, senão nos torna cada vez mais especialistas em nossa disciplina de origem. Somente assim se abre um leque mais amplo de conhecimentos, capaz de integrar os mais diversos acessos ao mundo. (FLICKINGER, 2010, p .53).

Nesse sentido, o "fundamento hermenêutico da interdisciplinaridade", proposto por Flickinger (2010, p. 45), está no encontro e na cooperação entre os diferentes seres das disciplinas por meio de um entendimento linguístico compartilhado. A própria noção do que semanticamente significaria um diálogo precisaria, nessa altura, carregar um sentido hermenêutico que é distinto de um processo metodológico ou 


\section{त w HEM Ellloahá}

ISSN: 1984-6444 | http://dx.doi.org/10.5902/1984644435441

propedêutico, mas que se revela no modo humano de se reconhecer na história, com o outro e diante das próprias criações. Do contrário, conforme Gadamer (2002, p. 244), "a incapacidade para o diálogo refere-se, antes, à impossibilidade de alguém abrir-se para o outro e encontrar nesse outro uma abertura para que o fio da conversa possa fluir livremente".

\section{Alguns possíveis desdobramentos de uma concepção hermenêutica da interdisciplinaridade}

O que indicamos até aqui, na esteira do pensamento hermenêutico e com a proposição do diálogo, foi uma possível forma de restabelecer, já no processo de formação, a unidade da experiência humana no mundo. Para isso assumimos o pressuposto hermenêutico de um mundo que só é mundo porque por nós humanos simbolizado. Mundo que só está para nós como linguagem, sempre nos convidando a sua interpretação, sem que esta jamais se esgote. Na imagem de Habermas, esse mundo deve ser entendido como "se fossem condensações e sedimentações dos processos de entendimento" (HABERMAS, 1990, p. 96), do que resulta que sua objetividade tem no falar humano como que a sua "matéria" constituidora, o seu princípio articulador.

Quando nos processos educativos buscamos apresentar o mundo às novas gerações, inserindo-as nos sentidos sociais e culturais historicamente construídos, sempre corremos o risco de esquecer o modo como esses sentidos constituíram-se passando a tomá-los como dados em si, sem historicidade, isto é, reificados. Em isso acontecendo, qualquer forma de conhecimento perde vitalidade, carece de sentido, uma vez que perde sua conexão com o âmbito de sua constituição, com o âmbito em que homens estabeleceram entre si um entendimento sobre algo que os afeta (a natureza, as coisas, as vinculações recíprocas, etc.). Mario Osorio Marques (1995, p. 24), ao tematizar a aprendizagem em contextos pedagógicos, chama a atenção para o risco de "uma cultura reificada numa materialidade mesmo que histórica ocultar a presença viva dos sujeitos que criativamente a movem". Recobrar o vínculo com esse pano de fundo do mundo da vida em que sujeitos produzem, mediante suas falas, 


\section{HsW Eutuabal}

ISSN: 1984-6444 | http://dx.doi.org/10.5902/1984644435441

tudo o que podemos tomar como conhecimento, é o que permite recobrar a unidade da experiência humana.

No percurso argumentativo deste texto, ao iniciarmos com a apresentação de uma percepção crítica do viés epistemológico presente nos entendimentos acerca da interdisciplinaridade, tínhamos presente que seriam em vão todos os esforços de "articulação de disciplinas" sem que estas se reconhecessem em seu vínculo com a experiência originária do mundo da vida que as engendrou. Ao entenderem-se como constituídas por alguma lógica que não a do falar humano, as disciplinas convertemse em entes coisificados, e, como tais, já não conseguem entrar em diálogo com as demais. Por isso, não se recobra a unidade da experiência da vida por um pretenso "integrar" de disciplinas reificadas. É preciso, antes, fazer com que essas voltem a se tornar vivas, compreendendo-se como historicamente constituídas e tributárias dessa experiência linguística fundante de tudo o que é humano e que necessita refazer-se continuamente. Enfim, por parte dos responsáveis pelas disciplinas requer-se a percepção de que as incursões parcializadas e legítimas que estabelecem no mundo, configurando-o, necessitam de contínuo dialogar com todas as demais disciplinas que, também a seu modo, fazem as suas incursões.

Podemos aqui usar a metáfora da mão para indicar o movimento que estamos sugerindo na direção do que chamaríamos de diálogo interdisciplinar. Imaginemos que o conhecimento, como explicitação de sentidos e de possibilidades das relações dos homens entre si e com a natureza, represente em sua unidade originária a palma da mão. Dessa unidade originária estabelecem-se incursões ao modo de especializações do conhecimento em função de um objeto e metodologia de ação próprios, que podemos imaginar como se fossem os dedos da mão. ${ }^{1}$ Pode-se observar como os dedos só se sustentam pelo fato de estarem encravados na palma da mão. E é exatamente a palma da mão que lhes confere mobilidade, possibilidades de articulação para além da palma, mas nunca sem ela. Um dedo que se desmembrasse seria, por óbvio, um dedo morto. Os dedos, por sua vez, só conseguem se articular a partir da palma da mão, que os une e permite que, inclusive, façam manobras conjuntas. Algum movimento de "religar os dedos" que, digamos assim, se "esqueceram" do seu vínculo com a palma, jamais poderá se fazer num 


\section{WFM Eutuabat}

ISSN: 1984-6444 | http://dx.doi.org/10.5902/1984644435441

âmbito para além ou fora da palma. Ligar os dedos amarrando as suas pontas, por exemplo, os deixa imobilizados, com o que perdem também a sua funcionalidade.

A metáfora da mão para pensar o movimento interdisciplinar nos permite dizer que disciplinas só conseguem se articular, sem perder a sua própria vitalidade, nesse espaço anterior àquele que representa o espaço de sua incursão especializada. Para isso é preciso que os discursos especializados consigam traduzir suas percepções para o âmbito da fala ordinária do mundo da vida, berço de onde todas as especialidades emergem. Não há nenhum outro âmbito a partir do qual se pudesse fazer algum tipo de integração disciplinar desejável. Também não há objeto prévio, ou realidade dada em si em função da qual ou para o qual, em algum momento, todos os discursos convergirão. Esse, na verdade, era o sonho da ontologia clássica e de um certo iluminismo científico que acreditava que cada ciência, ao "acender a sua luzinha", contribuiria para que, um dia, a realidade do mundo se apresentasse em toda a sua clarividência.

O movimento interdisciplinar, portanto, nos convoca ao desafio de traduzir todo o nosso saber num "saber dizer". É no dizer que os sentidos se configuram, se questionam e se reconstroem. É no saber dizer que encontramos a prevenção à reificação do nosso saber. O diálogo interdisciplinar exige, por sua vez, uma apreensão profunda e crítica do próprio campo disciplinar. Sem que os agentes de um campo disciplinar tenham a percepção clara do alcance e dos limites de suas incursões eles não conseguirão entrar num diálogo fecundo com outros campos disciplinares. Por isso não faz sentido falar de interdisciplinaridade sem um profundo saber disciplinar. ${ }^{2}$

\section{Considerações finais}

Organizamos aqui uma reflexão ancorada nos pressupostos da hermenêutica com vistas a pensar teoricamente as condições de possibilidade e os horizontes de sentido de uma pedagogia de caráter interdisciplinar. O importante em nossa empreitada teórica, ao que nos parece, foi buscarmos romper com o simplismo teórico 


\section{HEM Eutuabac}

ISSN: 1984-6444 | http://dx.doi.org/10.5902/1984644435441

como, também, com um certo pessimismo quanto à efetividade de um projeto pedagógico interdisciplinar.

Sabemos que a mera intenção de diálogo entre os representantes das disciplinas e o compartilhamento de conhecimentos produzidos não oferecem alcance suficiente para resolver as preocupações mais diretas da educação, principalmente no que diz respeito à qualidade de ensino. Por isso não apresentamos a interdisciplinaridade como a panaceia ${ }^{3}$ que resolveria definitivamente todas as nossas dificuldades. De outra parte, entendemos que é nosso papel enfrentar este tema com uma atitude crítica e reflexiva, focando sempre os possíveis sentidos dos processos de mediação do conhecimento em espaços educativos, bem como o lugar da própria docência.

Por fim, considerando não haver uma única forma de acesso à verdade e ao conhecimento, elegemos o diálogo como o horizonte de encontro entre as diferentes interpretações e visões de mundo. Dessa forma, vemos, na educação, a potencialidade da interdisciplinaridade na articulação da totalidade da experiência da vida, capaz de nos unir outra vez ao âmbito comum do qual emergimos e fazemos mundo, na condição de seres de linguagem.

\section{Referências}

BERTICELLI, Ireno Antônio. A origem normativa da prática educacional na linguagem. Ed. Unijuí, 2004.

BRASIL. Ministério da Educação. Parâmetros Curriculares Nacionais no primeiro e segundo ciclos do Ensino Fundamental. Brasília, DF, 1997.

BRASIL. Ministério da Educação. Parâmetros Curriculares Nacionais: Ensino Médio. Brasília, DF, 1998.

FAZENDA, I. Integração e interdisciplinaridade no ensino brasileiro: efetividade ou ideologia? São Paulo: Loyola, 1979.

FONSECA, Marília. O Banco Mundial e a Educação: Reflexões sobre o caso brasileiro. In: Gentili, Pablo. (Org.). Pedagogia da exclusão: o neoliberalismo e a crise da escola pública. (crítica ao neoliberalismo na educação) Petrópolis. RJ: Vozes, 1995. p. 77-108. 


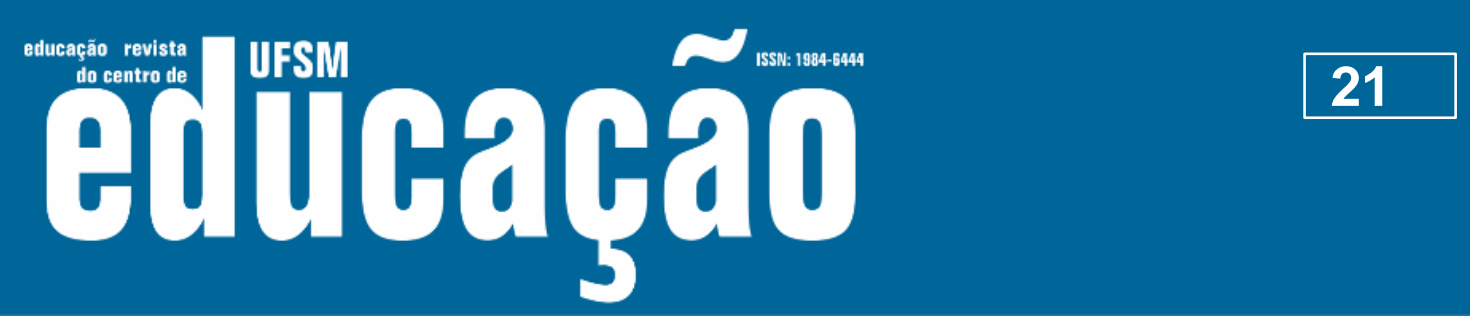

ISSN: 1984-6444 | http://dx.doi.org/10.5902/1984644435441

FLICKINGER, H. G. A caminho de uma pedagogia hermenêutica. Campinas: Autores Associados, 2010.

GADAMER, Hans-Georg. Verdade e método I: traços fundamentais de uma hermenêutica filosófica. Petrópolis, RJ: Vozes, 2012.

GADAMER, Hans-Georg. Verdade e método II: complementos e índice. Petrópolis, RJ: Vozes, 2002.

GALIAN, Cláudia Valentina Assumpção; LOUZANO, Paula Baptista Jorge. Michael Young e o campo do currículo: da ênfase no "conhecimento dos poderosos" à defesa do "conhecimento poderoso" (entrevista com Michael Young). Educação e Pesquisa. [online]. 2014, vol.40, n.4, pp.1109-1124. ISSN 1517-9702.

HABERMAS, Jürgen. Pensamento pós-metafísico: estudos filosóficos. Rio de Janeiro: Tempo Brasileiro, 1990.

JAPIASSU, H. Interdisciplinaridade e patologia do saber. Rio de Janeiro: Imago, 1976.

LAWN, Cris. Compreender Gadamer. Editora Vozes. Petrópolis, RJ. 1997.

MARQUES, Mario Osorio. A aprendizagem na mediação social do aprendido e da docência. ljuí: UNIJUÍ, 1995.

NAGEL, Lizia Helena. A crise da sociedade e da educação. Revista Apontamentos. UEM, n.9, 1992.

PALMER, R. E. Hermenêutica. Lisboa: Edições 70, 1997.

POMBO, Olga. Interdisciplinaridade e Integração dos Saberes. Liinc em Revista, v.1, n.1, março 2005, p. 3 -15.

\section{Correspondência}

José Pedro Boufleuer - Universidade Regional do Noroeste do Estado do Rio Grande do Sul, Departamento de Humanidades e Educação, Rua do Comércio, 3000, Universitário, CEP 98700-000, ljuí, Rio Grande do Sul, Brasil.

\section{Notas}

${ }^{1}$ Observamos que a metáfora da mão já foi usada para falar da relação das disciplinas com a totalidade da vida. Num texto de 1955, o físico norte-americano Julius Robert Oppenheimer escreve: "[...] O que temos em comum são os simples meios pelos quais aprendemos a viver, a falar e a trabalhar juntos. Além disso, temos as disciplinas especializadas que se desenvolveram como os dedos da mão: unidos na origem mas já sem contacto" (Oppenheimer apud POMBO, 2005, p. 7). 


\section{Xism Gutrathá}

ISSN: 1984-6444 | http://dx.doi.org/10.5902/1984644435441

${ }^{2}$ Nesse sentido, o sociólogo e pensador da educação Michael Young indica que é preciso que os estudantes aprendam as disciplinas e seus conceitos antes de a escola começar a trabalhar de forma interdisciplinar. Para ilustrar esse seu entendimento, ele dá o exemplo do tema do aquecimento global e das mudanças climáticas que, em seu entender, não poderiam constituir-se em tema de projeto interdisciplinar antes que os alunos tivessem aprendido o conceito de clima (GALIAN; LOUZANO, 2014, p. 1120).

${ }^{3} \mathrm{~A}$ expressão é uma metáfora usada neste contexto de discussão para comparar a interdisciplinaridade a um conjunto de medicamentos que, de forma urgente, cura patologias de um sistema.

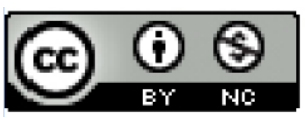

This work is licensed under a Creative Commons Attribution-NonCommercial 4.0 International (CC BY-NC 4.0) 